\title{
MARKETING INFANTIL: DESPERTANDO A BELA BIBLIOTECA ESCOLAR
} ADORMECIDA

\author{
Luana Narciso Rosendo \\ Bacharel em Biblioteconomia UFPB \\ luananarciso@hotmail.com \\ Maria Meriane Vieira Rocha \\ Mestre em Ciência da Informação \\ Professora do Departamento de Ciência da Informação \\ meriane.vieira@gmail.com \\ Angélica Clementino Simões \\ Mestre em Ciência da Informação \\ Coordenadora da Biblioteca do Colégio Pio X \\ angelicasimoesjp@hotmail.com
}

\section{Resumo}

Objetiva analisar o marketing e endomarketing realizado em cinco bibliotecas escolares de instituições privadas do Município de João Pessoa, aplicado para seus gestores com relação ao despertar de práticas de leituras integrado ao processo de ensino-aprendizagem. Descreve alguns conceitos de biblioteca escolar, fazendo menção a projetos de leituras e ao marketing. A metodologia foi constituída de caráter exploratória, articulada com pesquisa de campo, o instrumento de coleta de dados foi o questionário, contendo questões abertas e fechadas direcionadas aos gestores. Conclui-se que ajustes são necessários e as experiências com as atividades articulam o conhecimento e formas de fazer e assim, os usuários estão satisfeitos.

Palavras-Chave: Biblioteca Escolar. Marketing. Endormarketing.

\section{INTRODUÇÃO}

As bibliotecas, como espaços de informação, também foram inseridas nesse contexto de mudanças e há algum tempo utilizam as novas tecnologias de comunicação, no entanto, para êxito de qualquer informação. Nessa perspectiva, o marketing e suas técnicas auxiliam os gestores a definir seu mercado, criar e adequar o seu produto/serviço para que realmente alcance o público que dele necessite.

A biblioteca escolar funciona como um centro de recursos educativos, integrado ao processo de ensino- aprendizagem e tem como objetivo desenvolver a leitura e informação. As bibliotecas por muito tempo não utilizavam técnicas de marketing, hoje as aplicam compreendendo que o mesmo desenvolve a missão de atender as necessidades dos usuários.

Por esse anglo nosso objetivo geral é analisar as competências e habilidades dos bibliotecários, baseado nas atividades de marketing e endomarketing, voltadas para o público de biblioteca escolar infantil e juvenil e os específicos são: Descrever o perfil da biblioteca e dos bibliotecários; Categorizar os serviços oferecidos pelas bibliotecas; conhecer e descrever as ações de marketing que as bibliotecas escolares utilizam para atrair seu público.

A investigação a estas questões poderão evidenciar aos profissionais da área a importância do marketing direcionado ao público infantil e juvenil em bibliotecas escolares, assim, como nortear as atividades afins. 


\section{Anais do Encontro Paraibano de Biblioteca Escolar}

\section{A BELA BIBLIOTECA ESCOLAR}

O sucesso da biblioteca na escola vai estar ligado ao pessoal que nela atua e é necessário ter em mente: Quem é? O que faz? Como o faz? O professor como agente do processo ensino-aprendizagem e principal desencadeador das ações desenvolvidas na escola, deve atuar diretamente na formação e utilização do acervo, na formação do gosto pela leitura e pesquisa e análise crítica, selecionando criteriosamente o material, como também na escolha de atividades para que a Biblioteca Escolar faça parte do dia-adia do aprendizado aluno até tornar-se uma prática corriqueira.

Atualmente, a biblioteca escolar é vista como um lugar onde se desenvolve o processo educacional, onde se compartilha o conhecimento, estabelecendo uma mediação entre informação e usuário. Conforme Côrte; Bandeira (2011, p. 6) a biblioteca escolar:

Serve de suporte aos programas educacionais, atuando como um centro dinâmico, participando, em todos os níveis e momentos, do processo de desenvolvimento curricular e funcionando como um laboratório de aprendizagem integrado ao sistema educacional.

A principal atividade de um bibliotecário dentro de uma biblioteca escolar é atender as necessidades informacionais da escola, além das atividades técnicas, como também ser visto como um educador capaz de transmitir a essência da competência informacional.

Para Caldin (2003) o bibliotecário é o profissional ideal para gerenciar uma biblioteca escolar, a ele compete fazer com que esta unidade de informação funcione de modo apropriado e dinâmico. Para que sejam eficientes, os serviços de informação dependerão do talento, da competência e da habilidade de seus profissionais que devem renovar-se de maneira criativa.

Diante disso, o bibliotecário escolar é o profissional responsável pela gerência da biblioteca, ou seja, ele deve ser um agente proativo, para Silva (1999, p. 76), o bibliotecário escolar é:
Uma espécie de coordenador da biblioteca, responsável, como já denota o termo, pela coordenação das sugestões, ideias, atividades vindas de todos os pontos da escola, sempre visando à transformação da biblioteca escolar num espaço dinâmico e articulado com o trabalho desenvolvido pelo professor.

Dessa forma, observa-se que a biblioteca escolar está cada vez mais desempenhando novos papéis, deixando-se de ser apenas uma guardiã de livros, tornando-se um espaço multifuncional, ou seja, ela passa a ser um local para desenvolver um conjunto de atividades atualizadas e dinâmicas, de forma que a disseminação da informação seja apreendida pelos alunos.

\subsection{PEQUENOS USUÁRIOS, GRANDES LEITORES: Marketing para crianças.}

O desejo de descobrir o que existe nos livros, geralmente, existe em cada criança e adolescente, no entanto, cabe à escola e familiares desenvolvê-lo, utilizando toda a sua estrutura e filosofia adotada, bem como, todo seu espaço físico. Estimular e permitir que a criança desperte o desejo de conhecer o que há nos livros, é tarefa também dos bibliotecários, que devem estar sempre atentos a conquistar usuários leitores.

No plano de ação da biblioteca, o aluno, sobretudo, os do ensino fundamental, são muito atraídos pelo lado visual, devido à inteligência sensório-motora, período compreendido entre o nascimento e dois anos, nessa fase as crianças desenvolvem a capacidade de reconhecer a existência de um mundo externo a eles, tendo autonomia para explorá-lo e construir sua percepção de mundo.

A biblioteca escolar requer ações de marketing que formem mais profissionais conscientes e proativos. Ao falar em atividades possíveis de serem trabalhadas no espaço da biblioteca, estamos referindo-nos aos incentivos ao gosto pela leitura, à capacidade dos alunos de buscar, selecionar e interpretar as diferentes informações disponíveis no acervo, como:

a) Hora do Conto: essa é uma atividade tradicional na biblioteca. É importante que o 


\section{Anais do Encontro Paraibano de Biblioteca Escolar}

professor e o bibliotecário saibam identificar qual é o tipo de livro adequado para cada faixa etária dos alunos. O objetivo da "Hora do Conto" é contar histórias de forma alegre e agradável, a fim de atrair as crianças para o universo da literatura e dessa maneira, ajudar na formação de novos leitores.

As escolas precisam revitalizar o hábito de contar histórias, resgatando esta arte milenar. A contadora de histórias Busatto, (2003, p. 45-46) diz por que devemos contar histórias:

Conto histórias para formar leitores; para fazer da diversidade cultural um fato; valorizar as etnias; manter a História viva; para se sentir vivo; para encantar e sensibilizar o ouvinte; para estimular o imaginário; articular o sensível; tocar o coração; alimentar o espírito; resgatar significados para a nossa existência e reativar o sagrado.

Outro fator fundamental é a preparação do ambiente, pois, as crianças devem estar sentadas confortavelmente, e não deve haver ruídos que desviem a atenção delas enquanto a história estiver sendo narrada. Para criar expectativa, podem-se utilizar músicas, fantoches e teatro. O bibliotecário, também pode preparar a "hora do conto" utilizando CDs, vídeos e DVDs, dessa forma estará facilitando e dando mais recursos para o contador de histórias. O importante é que ao final da atividade, as crianças possam expor o que chamaram sua atenção, ou seja, interpretar a leitura e resumir o que foi lido.

b) Jogos educativos e recreativos: $O$ exercício de soletrar é sempre popular, outra ideia é fazer uma competição sobre a maioria dos livros lidos durante todo o ano ou fazer um gráfico que complete o progresso de cada criança, onde, elas podem provar que leram os livros concluindo um breve resumo.

c) Atividade no computador: Visto que os computadores da escola ficam quase que sempre nas bibliotecas, podem-se encontrar muitos aplicativos para as crianças trabalharem. Algumas ideias para atividades no computador, além da aprendizagem regular, são programas que ensinam aos alunos a como criar gráficos e que são lidos ao longo da aprendizagem.

d) Exposições de livros: A biblioteca deve manter uma exposição permanente de livros recém-chegados, bem como de outros documentos de interesse, a fim de divulgar conhecimento e informação. Assim, apresentar o livro e a leitura as crianças é um desafio, alguns obstáculos precisam ser vencidos. $\mathrm{O}$ bibliotecário precisa assumir o seu papel de mediador, direcionando as suas atividades para os interesses dos alunos, ser criativo e estar disposto a interagir com eles.

Dentre essas atividades, temos muitas outras, como: familiarizando-se com a biblioteca, conhecendo os materiais impressos, varal literário, peças teatrais e etc. No entanto, o que se deve ter em mente é como o bibliotecário vai desenvolver de forma criativa essas atividades, sempre com o intuito de atrair os docentes para a Biblioteca, onde esta deve ser vista como o lugar do aprendizado prazeroso.

\section{METODOLOGIA}

$\mathrm{O}$ estudo consiste em uma pesquisa exploratória, utilizando-se de um estudo de caso. Neste contexto, o estudo é de natureza quali-quantitativa. Quanto à tipologia, a pesquisa pode ser considerada como bibliográfica, do tipo levantamento e descritiva.

O universo de bibliotecas escolares de Instituições privadas do Município de João Pessoa é amplo, considerando essa amplitude, trabalhamos com uma amostra de 05 bibliotecas de colégios particulares e que atende crianças da Educação Infantil até o Terceiro ano do Ensino Médio, denominadas: Colégio Lourdinas; Externato Santa Dorotéia; Colégio João XXIII; QI Colégio e Curso; Colégio Século.

\section{AÇÕES DE INCENTIVO A LEITURA}

Sobre as ações das bibliotecas a respeito dos incentivos a leitura que as mesmas proporcionavam aos seus usuários. 


\section{Anais do Encontro Paraibano de Biblioteca Escolar}

Gráfico 1 - Ações que promovem o incentivo a leitura.

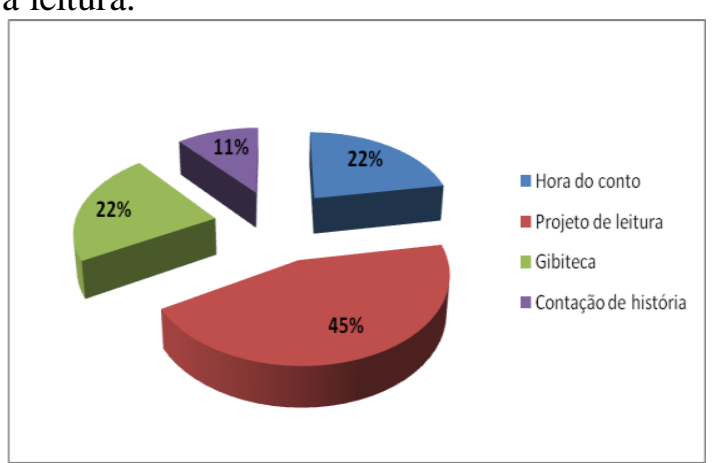

Fonte: Pesquisa de campo, 2014.

Projetos de leituras é o foco com maior percentual praticado pelas bibliotecas escolares. Esses projetos são voltados para divulgação do acervo, premiações aos alunos que realizou mais empréstimos, exposições de murais, gibiteca, concurso de contação de histórias, realização de feiras de livros,

A gibiteca e hora do conto são as duas atividades que ficaram com segundo maior percentagem, seguido da contação de histórias. É salutar perceber que a gibiteca obteve um resultado significante, afinal, percebemos que o preconceito que havia com o passar do tempo foi superado e os educadores passaram a se apropriar dos quadrinhos nos trabalhos de incentivo a leitura.

Em seguida, foi interesse saber da aplicação das técnicas do marketing utilizadas pelas bibliotecas:

Gráfico 2 - Técnicas de marketing

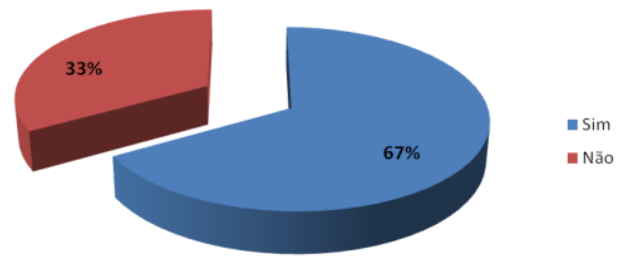

Fonte: Pesquisa de campo, 2014.

Conforme descreve o gráfico, concluímos que $67 \%$ dos entrevistados relatam que as técnicas de marketing utilizadas para estas ações são: exposições de quadros e cartazes, mídia impressa, jornais, exposição de datas comemorativas, divulgação de oficinas, sarau com escritores, contação de histórias e rodas de leitura.

No gráfico a seguir foi questionada a utilização da biblioteca por parte dos professores, visto que, em bibliotecas escolares, o uso da mesma é feita ou deveria ser feita através deles.

Gráfico 3 - Utilização da biblioteca pelos professores

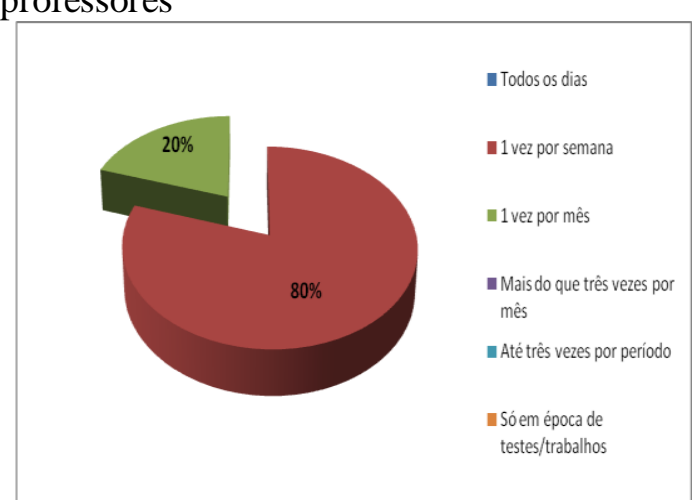

Fonte: Pesquisa de campo, 2014.

A partir das respostas ao questionário sobre a frequência dos alunos e professores na biblioteca, verificou-se que totaliza grande parte como sendo o espaço utilizado uma vez por semana, estes representados em $80 \%$ para consultar o acervo, realizar empréstimos, estudar em grupo ou individualmente, realizar pesquisas e utilizar os computadores.

E $20 \%$ dos entrevistados informam que basicamente utilizam a biblioteca uma vez por mês. Por vários motivos: falta de interesse, estimulo e motivação dos usuários. Nesse contexto Freitas (1986) explica que a falta de hábito de alguns professores em utilizar livros como recurso de ensino - aprendizagem demonstrou que a metodologia por eles utilizada, sem a orientação do grupo, poderá provocar nos seus alunos certa rejeição pela leitura com lazer.

E com relação à divulgação da biblioteca? Certamente que iríamos perguntar a respeito e tivemos os seguintes dados? 
Gráfico 4 - Promoção/divulgação da biblioteca.

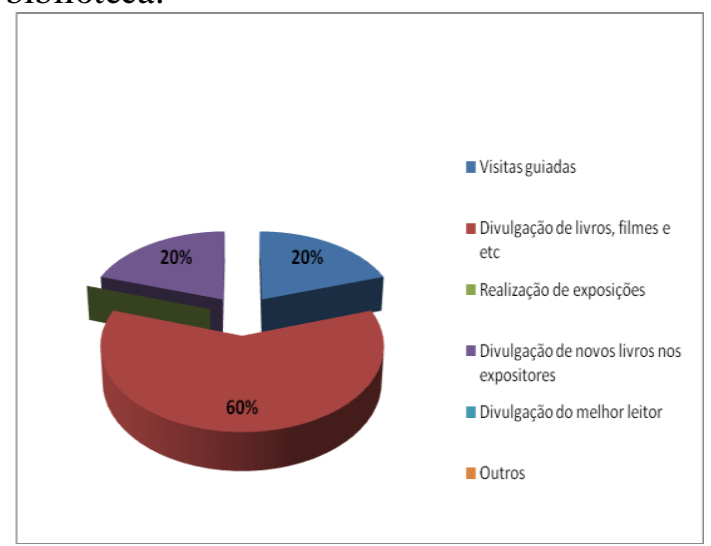

Fonte: Pesquisa de campo, 2014.

O gráfico anterior nos mostra sobre a promoção e divulgação da biblioteca, que em sua maioria sendo representada com $60 \%$, verificou que a realização de exposição lidera em seguida visitas guiadas e divulgação de novos nos expositores com $20 \%$.

Os principais produtos da biblioteca escolar são voltados à educação, ou seja, deve ser um local em que os alunos possam ter um contato com o livro de forma livre, estimulando a criatividade a partir de brincadeiras e jogos e o contato com os livros se dê de forma natural partindo do próprio aluno (PRADO, 2003).

A seguir, perguntamos se os bibliotecários realizavam algum tipo de planejamento com professores e coordenadores das respectivas escolas.

Gráfico 5 - Planejamentos professores/bibliotecários

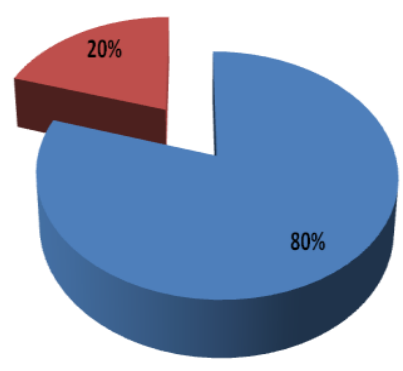

Fonte: Pesquisa de campo, 2014.

$\mathrm{Na}$ totalidade dos entrevistados que participam da formação e planejamento com os professores, $80 \%$ responderam que participam assiduamente junto ao corpo pedagógico da escola, enquanto que $20 \%$ não participam e ainda planejam serviços pedagógicos, recomendáveis para bibliotecas escolares, sendo eles: feira de livros; encontro com o autor, fantástica oportunidade para o aluno ter contato com o escritor ou escritora cujo livro leu e o despertou para o mundo da leitura; concurso de poesias; comemoração de datas importantes, cívicas ou didáticas; sarau literário; exposições temáticas, que podem ser apenas para visitação ou onde os usuários podem interagir, ativamente, com o ambiente de exposição; entre outros.

Dessa forma, podemos considerar que de forma direta ou indireta o professor utiliza o espaço e serviços da biblioteca, de acordo com o planejamento obtido entres eles.

Por fim, tivemos o interesse de perguntar sobre a percepção dos usuários com os serviços da biblioteca:

Gráfico 6 - Satisfação dos usuários

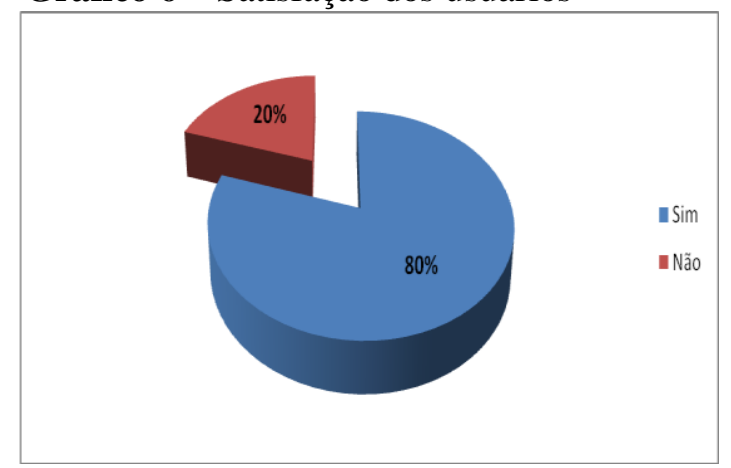

Fonte: Pesquisa de campo, 2014.

Na maior parte dos entrevistados, o nível de satisfação com os serviços da biblioteca foram de $80 \%, 20 \%$ responderam que não. Quando o bibliotecário der sua devida atenção às atividades inerentes a uma biblioteca, ele permite que o usuário manifeste suas expectativas, quando ouvindo com interesse e solucionando seus problemas ou dúvidas.

Hoffman e Bateson (2003) colocam que é preciso que a biblioteca defina e meça a satisfação dos usuários, nunca devendo esperar por reclamações para então identificar os problemas na prestação de serviços.

Antes da biblioteca querer melhorias em seus níveis de satisfação, deve primeiro descobrir se seus usuários estão satisfeitos ou insatisfeitos, o que pode ser feito com uma 
avaliação de satisfação. Usuários satisfeitos disseminam informações positivas, reduzindo o custo para atrair novos usuários, segundo Lovelock e Wright (2001, p.30) "a qualidade dos serviços é percebida, muitas vezes, nos detalhes, e o conceito de qualidade, então, deve levar em conta o processo humano, se for o caso, na geração do serviço".

\section{CONSIDERAÇÕES FINAIS}

No presente estudo analisamos as ações do marketing e endomarketing aplicado ao público infantil e juvenil das bibliotecas escolares de Instituições Privadas no Município de João Pessoa, a fim de incentivar as unidades de informação a adotar a administração orientada para o marketing e endormaketing como ação inovadora, capaz de melhorar os serviços oferecidos por essas organizações.

O Marketing surgiu de acordo com a necessidade e desejo do bibliotecário em tornar seu espaço de trabalho atrativo e que tornasse para o leitor um momento de prazer.

$\mathrm{O}$ estudo analisou os dados coletados que sugerem ações de marketing e endomarketing e competências da informação, dessa forma constataram um grande campo de atuação: a internalização do marketing em unidades de informação, demandadas pelos profissionais bibliotecários nas bibliotecas escolares.

Os gestores das unidades que aplicam ações que seguem a filosofia do marketing dentre elas: motivar, capacitar, resolver conflitos, valorizando e despertando o interesse das pessoas que integram sua equipe, sempre em busca de excelência profissional através dos serviços prestados pela biblioteca, inserido nesse contexto o bibliotecário, tornando-se um gestor de pessoas, assumindo outra função dentro da organização.

Estes gestores identificam os usuários como, consumidores de informação, e é em função deles que as bibliotecas existem e sobrevivem. Para contribuir com o crescimento e reconhecimento da instituição biblioteca e do bibliotecário como profissional da informação, é preciso conhecer, envolver, valorizar e atender bem o seu público. Dessa forma sendo vista como prática importante que contribui para a consolidação desse profissional no mercado do trabalho.

É interessante desenvolver atividades similares a está em outras escolas, para que avalie a postura proativa do bibliotecário e busque meios que gerem oportunidades para o aperfeiçoamento deles, de forma que desenvolvam habilidades em outras áreas, a fim de se tornar um profissional proativo e ter uma educação continuada. Nesta pesquisa conclui-se que ajustes são necessários e importantes, e as experiências com as atividades articulam o conhecimento e formas de fazer.

Conclui, ainda que os usuários estejam satisfeitos. Contribui para estimular estudos e pesquisas sobre o marketing infantil, na área da biblioteconomia e ciência da informação.

\section{REFERÊNCIAS}

BUSATTO, Cléo. Contar e encantar pequenos segredos da narrativa. Petrópolis: Vozes, 2003.

CALDIN, C. F. A função social da leitura na literatura infantil. Enc. Bibli: R. Eletr. Bibliotecon. Ci. Inf., Florianópolis, n. 15, $1^{\circ}$ sem. 2003.

CÔRTE, A. R.; BANDEIRA, S. P. Biblioteca

Escolar. Brasília: Briquet Lemos, 2011.

FREITAS, M. T. Educação pela leitura: uma experiência. Florianópolis: Perspectiva, 1986.

HOFFMAN, K. Douglas; BATESON, John E. G. Princípios de marketing de serviços: conceitos, estratégias e casos. São Paulo: Thomson, 2003.

LOVELOCK, Cristopher H.; WRIGHT, Lauren. Serviços: marketing e gestão. São Paulo: Saraiva, 2001.

PRADO, Heloísa de Almeida. Organização de bibliotecas. 2 ed. São Paulo: T. A. Queiroz, 2003. 
SILVA, W.C. Miséria da biblioteca escolar.

São Paulo: Cortez, 1999. 